\title{
DEVELOPMENT OF COLLABORATION IN THE ENGLISH FOR SPECIFIC PURPOSES COURSES: OPPORTUNITIES AND CHALLENGES
}

Evelina Jaleniauskienė, Robert Leščinskij, Palmira Jucevičienė

\author{
Kaunas University of Technology, Vilnius Gediminas Technical University, Lithuania \\ E-Mail: ktu@ktu.lt
}

\begin{abstract}
The mission of higher education institutions is to prepare future professionals for a rapidly changing labor market, yet what skills we teach students, and how we teach them, is highly problematic. The ability to collaborate is crucial for success in professional and academic endeavor; the challenge for foreign language educators is to shift the focus of courses in ways that address the development of collaboration skills. Yet, this also becomes a challenge in scholarly literature on English for Specific Purposes (ESP), since research in this field has been somewhat limited, i.e., most commonly it investigates collaborative writing as a way of developing collaboration. Furthermore, the explicit teaching of collaboration, as well as the inclusion of diverse tasks to enhance collaboration, are often neglected by researchers. Also neglected in this field of research are the challenges and opportunities that students experience while learning to collaborate during ESP classes. The paper aims at acquiring more in-depth insights into the phenomenon of collaboration during ESP classes to facilitate the practice of language educators who can no longer neglect the urgent need to develop collaboration through their classes. The authors of the paper, who were also the designers of ESP tasks, sought to develop collaboration skills by both engaging learners in collaborative tasks and integrating additional measures to address this skill. Qualitative data acquired via observations and semi-structured interviews revealed that such tasks could contribute to students' overall performance to improve language proficiency because they enhance motivation and engagement. Apart from collaboration skills, they contribute to the development of many essential skills vital for engagement in the twenty-first century workplace. Notwithstanding, they pose challenges to students and this indicates the need for more frequent collaborative tasks and progress with additional measures that develop students' collaboration abilities in higher education.
\end{abstract}

Key words: collaboration, English for specific purposes, higher education, problem solving

\section{INTRODUCTION}

The task of universities is to prepare graduates for today's dynamic and challenging national and international labor markets. At the same time, higher education institutions need to find ways to manage limitations imposed by changes in the global situation, i.e., demographic changes in particular countries, government budget restrictions and excessive, and sometimes unreasonable expectations of stakeholders. If Newman's (1889) 
idea of the university was primarily that of an institution concerned with knowledge dissemination through the interaction of students with the faculty and participation in academic life on campus, the contemporary university expands far beyond the campus nexus. To succeed, and be seen to succeed, it must form partnerships with industry, public institutions, or particular individuals, in the hope that they can contribute to the quality of student education and/or research. In return, mission statements of universities usually 'promise' to train highly qualified staff for their partners beyond the campus. Thus, university graduates are expected to have a thorough grasp of their subject area, a wide range of skills, and be able to easily assimilate into the partner, employing organizations. Yet, this is easier said than done. Autor, Levy, and Murnane (2003) point out the changing situations in labor markets, claiming that non-routine tasks are continuously replacing routine labor performed manually. Technology has replaced workers who perform routine work, while it complements workers with higher-level skills and empowers them to be more productive and creative (Autor, Levy \& Murnane, 2003). This new paradigm of performance demands revisiting the goals of education.

The extent of change is astonishingly fast so that many jobs of the future do not yet exist, which begs the question: what skills will students need in the future if they are to be better prepared to join tomorrow's workforce? This issue, centered around skills, has been the subject of much debate by education researchers and job market policymakers over the last decade. From out of this debate a new term emerged which describes the set of essential skills needed in modern societies, i.e., $21^{\text {st }}$ century skills (Csapó \& Funke, 2017). Typical skills in various frameworks (e.g., Assessment \& Teaching of $21^{\text {st }}$ Century Skills, Framework for $21^{\text {st }}$ century learning, Partnership for $21^{\text {st }}$ century skills) usually include communication, creativity, innovation, collaboration, information and communication technology literacy, critical thinking and problem solving (Häkkinen et al., 2017). Most of the frameworks in question list collaboration among the top skills. Noteworthy is a contemporary approach that presents collaboration as an appropriate replacement for competition in many disciplines and areas of life. Employers also indicate collaboration to be among the most desirable skills in employees (World Economic Forum, 2016). It is unsurprising that in the wake of the fourth industrial revolution, collaboration is predicted to remain among the main prerequisites for successful performance on both individual and organizational levels for the decades to come (Schwab, 2017).

In view of the importance of collaboration in current and future organizations, the development of this skill should be addressed in university studies. To this end, university programs already include collaboration as an intended learning outcome, usually in terms of a developed social skill. However, it is often done in a declarative way and lacks methodological support, i.e., selected learning/teaching methods do not match the intended learning outcome. One instance of this was a review of certain educational practices across various levels of education, conducted by Lai et al. (2017), revealed that students need both more practice in, and enhancement of, collaboration. At the same time, researchers (cf. Saavedra \& Opfer, 2012; Jucevičienè \& Vizgirdaitè, 2012; Lai et al., 2017) agree that student involvement in collaborative activities alone is insufficient for the development of collaboration skills. Thus, educators need to develop and integrate more professional guidance to support the development of this skill. Indeed, research findings confirm that the explicit teaching of collaborative skills yields better collaboration among learners (e.g., Jucevičienè \& Vizgirdaite, 2012; Lai et al., 2017). Such findings suggest careful consideration of additional measures to enhance collaboration. 
No matter how conservative, language educators should adopt this change to assist students to master $21^{\text {st }}$ century skills instead of zeroing in on learning 'about' language. The focus should be expanded to learning with, or through, language (Camaratta et al., 2016). The current paper contributes to this movement. In addition, learning by inclusion in collaborative discourse while performing authentic and open-ended tasks (e.g., projects or scenarios) is advocated by the action-oriented approach, which is considered to be the most up-to-date approach for the teaching and learning of foreign languages (Piccardo \& North, 2019). Introduced in the Common European Framework of Reference for Languages: Learning, Teaching, Assessment (hereafter the CEFR; first published in 2001), this approach marks a paradigm shift in foreign language education (Piccardo \& North, 2019). Building on both sociocultural and socio-constructivist theories, action-oriented approach stresses the crucial importance "on the use of tasks in collaborative group work, on discovery learning, and collective problem solving" (Piccardo \& North, 2019, p. 74). Therefore, placing language learners in collaborative learning contexts is consistent with the latest ideas on modern foreign language education.

The intention of this paper is therefore to select a broader range of activities to develop collaboration in ESP classes. In addition, it will identify additional explicit measures and more diverse means that encourage and enhance collaboration among group members. Accordingly, the research question has been formulated as follows: what opportunities and challenges are experienced by students engaged in collaborative tasks that explicitly aim to develop collaboration skills. The study aims at acquiring more in-depth insights into the phenomenon of collaboration in ESP classes to facilitate the practice of language educators who can no longer neglect the urgent need to develop collaboration through their classes. Qualitative data was collected through observations and semi-structured interviews with students. Both student perspectives and teacher observations were considered.

\section{LITERATURE REVIEW}

\subsection{Collaboration in learning}

While earlier learning theories (like behaviorism and cognitivism) devoted (undeservingly) little attention to the social context of learning, modern approaches stress the importance of student interaction for learning. Upon the introduction of social theories such as Vygotsky's social constructivism, researchers started considering the importance of the dialogic power for the learning process. Learning is now seen as "inherently a socialdialogical process" (Jonassen \& Land, 2012, p. x). Dialogue is understood as a powerful aspect of learning, through which learners share their understanding and modify it, whereas isolated ideas of an individual have no such power. More importantly for this paper, the Vygotskian thought delegates language a special mission. It is Vygotsky himself who noticed the two-fold function of language, where it is seen, first as a communication tool for jointly sharing and developing knowledge, and second, as a psychological tool for organizing, planning and reviewing thoughts and actions. The Vygotskian school stresses that learning is generally a social process. Therefore, the social interactions that learners are engaged in have enormous significance for learning. The main idea of sociocultural theory is that learning, including foreign language learning, is "a semiotic process where participation in socially mediated activities is essential" (Turuk, 2008, p. 244). It should be a collaborative 
achievement rather than an isolated individual effort where a learner works unassisted and unmediated (Turuk, 2008).

As far as ESP classes are concerned, learning in a collaborative context also goes in line with the recently advocated necessity to take up action-oriented approach (hereafter the AOA) to foreign language learning. The approach is encouraged by the updated CEFR (Council of Europe, 2018), recently published in the updated online provisional edition (known as the CEFR Companion Volume with New Descriptors). The CEFR serves as the primary document advising on teaching, learning, and assessment of foreign languages in Europe. The central methodological message of the CEFR is "that language learning should be directed towards enabling learners to act in real-life-situations, expressing themselves and accomplishing tasks of different natures" (Council of Europe, 2018 p. 27). Namely, the AOA requires engaging learners in purposeful communication by performing open-ended and authentic tasks that are close to real life and have both linguistic and non-linguistic goals (Piccardo \& North, 2019). Besides, each actionoriented task of a language class should engage learners in both critical and creative thinking, as well as result in the creation of learning artifacts (Piccardo \& North, 2019).

In comparison to the communicative approach (also known as communicative language teaching), which has been dominant for a long time in foreign language education, the AOA is a more recent development. The communicative approach is also close to real-world language use as it teaches the use of a foreign language in a variety of contexts and functions using communication as a learning tool. However, communication becomes more meaningful in the AOA. According to the AOA, language learners act "primarily as 'social agents', i.e. members of society who have tasks (not exclusively language-related) to accomplish in a given set of circumstances, in a specific environment and within a particular field of action" (Council of Europe, 2001, p. 9). They perform various actions that have goals other than just communicating or learning to communicate. Indubitably, this results in more purposeful communication among learners. Moreover, the AOA stresses the importance of a social context where learning takes place. Piccardo (2014) explained that this involves two types of interactions - among learners, as well as between the learner and the external context. Thus, while CLT outlines learning through communication and in communicative situations, the AOA adds two more dimensions learning with others and in some specific situations or contexts, which in turn influences learning by providing some conditions or constraints.

New working environments are increasingly requiring collaborative efforts to solve complex problems and develop innovative solutions. The most recent shift in foreign language learning/teaching methodological and epistemological paradigms promoted by the CEFR (Council of Europe, 2018) and the challenges of labor markets, force educators to seek creative solutions for providing learners with authentic and action-oriented tasks which simulate real-life activities (e.g., projects, problem-solving scenarios). Such activities provoke meaningful communication among learners in a foreign language as well as engage them in collaborative activities. Such a shift implies significant changes for language educators. With foreign language learning becoming more sophisticated (Piccardo \& North, 2019), educators' tasks are becoming more complicated too. Additional demands for them are imposed in cases when they have to deal with the social aspects of learning. 


\subsection{Social aspects of collaborative tasks and enhancement of collaboration}

Collaboration can be defined as "the activity of working together towards a common goal" (Hesse et al., 2015, p. 38). It includes several subskills, which educators have to consider for better understanding and further development of students' collaboration skills in their courses. After summarizing a number of frameworks that dealt with collaboration, Lai et al. (2017) concluded that it requires interpersonal communication (using supportive and open communication), negotiation (performance management, goal setting, planning, and task coordination), conflict resolution (ability to distinguish between constructive versus destructive conflict and apply conflict-resolution strategies), and task management. Collaboration involves communication (exchange of ideas), teamwork and responsiveness (thoughtful and active participation) (Hesse et al., 2015). More specifically, Hesse et al. (2015) established a comprehensive framework for collaborative problem-solving skills, which includes two main classes of skills - social and cognitive. As far as social collaboration skills are concerned, the authors distinguish among participation, perspective taking, and social regulation. As explained by Hesse et al. (2015), participation refers to readiness and willingness to share thoughts and information, which goes beyond mere presence in the collaborative process. Perspective taking is the ability to see a problem or situation through the eyes of other collaborators, and social regulation refers to various strategic aspects during collaborative problem solving - selfevaluating, negotiating, initiative and responsibility-taking (Hesse et al., 2015). Thus, each group member is expected to display initiative, negotiate and share responsibility for the task in order to accomplish it. Various types of collaborative assignments, including the ones carried out in the language class, require these skills.

Researchers agree that learners lack the skill of collaboration in general (e.g., Jucevičienè \& Vizgirdaite, 2012; Lai et al., 2017). Another important observation is that involvement in collaborative tasks alone does not guarantee the development of this skill. Lai et al. (2017) pointed out that collaboration is not a skill that students can learn on their own because students may lack feedback on what has been done incorrectly and the ways to improve it, for example, by receiving feedback on their collaborative efforts. What researchers conclude is that additional efforts directed at facilitating student collaboration contribute to the effectiveness of collaboration and the development of this skill (e.g., Prichard et al., 2006; Jucevičienè \& Vizgirdaité, 2012; Lai et al., 2017). Therefore, for better results, the skill has to be addressed deliberately.

As far as the explicit techniques to enhance collaboration are concerned, they could include the following: explaining students why the skill is essential, encouraging group members to share the task and responsibility fairly, learning to disagree appropriately, teaching ways to resolve conflict, providing checklists of good behaviors (Lai et al., 2017). In addition, as an effective way to encourage appropriate collaborative performance, researchers and practitioners suggest using performance rubrics (Jonassen, 2011), which include instructional guidelines on expected performance. They could serve both for the assessment purposes (students know in advance what evaluation consists of) and for directing their performance before engagement in the tasks. For example, teams of experts from various American universities and colleges (Association of American Colleges and Universities, 2009) developed such teamwork rubric. Its purpose is to assess teamwork of an individual learner and not the team as a whole. The mentioned rubric is available for download from https://www.aacu.org/value/rubrics/teamwork. 
Vizgirdaite and Jucevičienè (2012) investigated the issue of determining students' collaboration competence. To assess learners' competence of collaborative learning and to subsequently empower them to learn collaboratively, the researchers applied Vygotsky's (1986) notion of three potential levels of learner's development. If a student is in the zone of actual development, he or she possesses not only important subject related knowledge but also knows how to act in the contexts of collaborative learning, i.e., has abilities, knowledge, and attitude required for collaboration. Those learners that lack both subject and collaborative knowledge are in the zone of proximal development, where they can receive help from more knowledgeable peers in order to advance to the zone of actual development. Finally, while in the zone of potential development, learners do not possess either required subject-related knowledge or collaboration competence. To continue, they need to acquire a certain amount of knowledge and understanding of collaboration in order to advance to either the zone of actual development (it is quite complicated in practice), or to the zone of proximal development. As an important measure to address collaboration, Vizgirdaitè and Jucevičienè (2012) suggest surveying students before engaging them in collaborative learning processes to determine their collaboration skills.

As far as the development of collaboration skills in ESP classes is concerned, scholarly literature seems to be somewhat 'unidirectional', in a sense that the bulk of it focuses on investigating the effects of teaching collaborative writing (e.g., Wang, 2015; Miyazoe \& Anderson, 2012; Shehadeh, 2011; Rollinson, 2005). In other instances, research on learning to collaborate is limited to the investigation of activities where students are divided into groups with little scaffolding (Chen \& Hird, 2006), which is a necessary condition for the enhancement of collaboration skills in ESP classes.

\subsection{Features of collaboration}

Educational researchers and practitioners report several features that collaborative tasks entail. A typical collaboration barrier mentioned by Steiner (1972, as cited in Hesse et al., 2015) is 'process losses', which means that some group members drop out for some period of collaboration. Cohen (as cited in Jucevičienè \& Vizgirdaitè, 2012) refers to this issue as not equal participation of each group member. Hesse et al. (2015) list several reasons that may cause process losses. It can be caused by the lack of motivation of group members or by the fact that not all group members adequately monitor and evaluate their activities and progress. Häkkinen et al. (2004) warn that in cases when not each group member fully understands the task, some of them may not wish to continue to interact. The reconstruction of shared understanding may require additional time and effort, which may distract other group members too. As observed by Hesse et al. (2015), groups may lack the quantity of externalization of thoughts and sharing of information. Coordination among members may prove to be difficult if learners do not invest enough effort to understand each other. Sardamalia (as cited in Hesse et al., 2015) warns against the cases of insufficient collaborative responsibility which may cause a complete failure of a collaborative task. Having analysed collaboration in problem-solving activities, Roschelle and Teasley (1995) found common problems of impasses when group members cannot reach an agreement. After investigating the phenomenon of collaborative problem solving, Ge and Land (2003) report possible off-task chatting and joking, which is common when individuals communicate. Such conditions may result in a worse performance of a group 
and prevent it from the full usage of its members' abilities and resources (Hesse et al., 2015).

Another common problem is students' lack of understanding of collaboration by simply equating it to cooperation. The research into collaboration and cooperation conducted by Vizgirdaite (2013) revealed that cooperation is oriented towards the distribution of tasks and achieving individual goals, whereas collaboration is based on mutual goals achieved through collective work, shared understanding and interdependent responsibilities, which result in coproduced outcomes. For example, Ge and Land (2003) observe that learners tend to divide their work depending on each student's expertise, especially when the time for the tasks is ending. The research results reviewed by Lai et al. (2017) confirm the fact that assignment into roles is beneficial in the learning process since students can become more active, responsible, and interested. On the other hand, it may also imply the probability of cooperation rather than actual collaboration (Strijbos et al., 2004).

One more common challenge for students is not a suitable type of talk among them. Mercer (2009) suggests exploratory talk during which group members are supposed to clearly explain their ideas by supporting them with arguments, explore various options, present reasons for their suggestions and try to understand perspectives of their colleagues. According to Mercer (2002), such discourse among collaborators ensures better learning results as learners not only brainstorm ideas for reaching the goal but also provide arguments to support their ideas. On the other hand, contributions in the form of disputational talk mean criticizing ideas without clear arguments, short claims and counter-claims and disputes between group members (Mercer \& Wegerif, as cited in Fernández et al., 2001). Similarly, cumulative talk is also less beneficial because students rely on repetitions, adding short, and often incomplete ideas, in the manner of brainstorming (Mercer \& Wegerif, as cited in Fernández et al., 2001). Researchers suggest that exploratory talk can be encouraged by explaining to learners what it means and establishing ground rules (principles that underline talks) for collaboration (Fernández et al., 2001; Warwick \& Mercer, 2011).

In the ESP classroom, effective collaboration is unlikely to be successful if some of the group members are resistant to participating in speaking activities. This withdrawal or partial withdrawal can have various causes. In the research literature, a phenomenon when students face the anxiety of speaking is referred to as reticence ( $\mathrm{Li} \& \mathrm{Liu}$, 2011). Several causes may lead to students' communication anxiety in class. Inability to properly participate in class discussions might result from low self-esteem, fear of being ridiculed, cultural differences among group members, communication apprehension (fear of communication with the rest in the presence of others), among others (Li \& Liu, 2011).

\section{METHODS}

\subsection{Educational tasks for the development of collaborative skills through ESP}

The authors sought to develop collaboration skills by both engaging learners in the collaborative tasks and integrating additional measures to address this skill. The collaborative tasks included:

1) Collaborative problem solving (involvement of students in 'pros and cons' type debates). Students were provided with ill-structured problems and asked to collaboratively come up with solutions. The problem for this task was formulated as a question: How can universities foster creativity in students? Students were given time to discuss the notion of 
creativity and had to come up with a definition of the term. After defining creativity, they were asked to develop as many solutions to the given problem as possible. As a linguistic aspect, students were provided with the lists of proper sentence structures and lexical items for the presentation of their ideas. In the following stage, students had to provide argumentinformed pros and cons for each idea. Finally, the ideas were reviewed considering the contributions of each group member and collaboratively presented to other groups. In addition, learners were suggested to employ web 2.0 tools (online platforms) as boards for putting down their ideas and presenting arguments and counter arguments for them. Two particular platforms were suggested: www.tricider.com and www.kialo.com. Both platforms are crowdsourcing tools that facilitate collaborative decision-making.

2) Group mind mapping (a type of visual thinking technique). Students have studied the technique of mind mapping as proposed by Tony Buzan (2006) and watch short videos explaining it on YouTube (e.g., Rules for Mind Mapping). For the next step, they a set of complex topics related to their major was suggested for them (e.g., the new EU General Data Protection Regulation). Students were asked to map the topics collaboratively. Again, students were encouraged to use the tools that allow synchronous collaboration, i.e., all group members can access the same mind map by sharing the link to it (c.f. Mindmeister.com).

3) Collaborative presentations. Students were given the task to create collaborative presentations. The ideas for presentations were inspired by popular type of YouTube videos which criticize mistakes in movies (Everything wrong with...). Students were asked to choose TED talks on technology-related issues, discuss them collaboratively using www.tricider.com, or www.kialo.com, and then make collaborative presentations and present them together for other learners. In addition, students were provided with the recommended lexical items and a set of suitable syntactic structures for their presentations. Prior to delivering their presentations, the learners were introduced to some insights into delivering presentations collaboratively (both positive and negative examples were analysed). Again, they were encouraged to use tools that allow creating presentations in collaborative mode (e.g., Google slides, Prezi, or any other online tool).

Before engaging learners in the tasks described, the authors integrated the following additional explicit measures to enhance and facilitate collaboration among students:

I. At the beginning of the course, ground rules were established together with students in order to ensure more efficient collaboration. They included the following rules:

- All important information relevant to the goal of the activity is shared among colleagues in the spirit of open collaboration and consensus-seeking (SHARE INFORMATION),

- Participants assume equal responsibility for the final product of the group work and share goals (SHARE RESPONSIBILITY AND GOALS EQUALLY),

- All opinions are welcomed and treated as equally important for the process and the goal alike (SHARE OPINIONS BECAUSE THEY ALL MATTER),

- Constructive criticism, based on arguments and directed towards the idea itself rather than means of expressing the idea is the only acceptable form of criticism (BASE CRITICISM ON ARGUMENTS ONLY),

- Equal time of participation is desired (PARTICIPATE EQUALLY),

- Friendly endeavor to understand each other's point of view should be present (MAINTAIN FRIENDLY ATMOSPHERE). 
II. Explicit instruction on collaboration. The students were explained about the differences between collaboration and cooperation in order to avoid this common misconception. Since Generation $\mathrm{Z}$ students rely best on videos, the authors employed some video footage from YouTube (e.g., Cooperation vs Collaboration: When to Use Each Approach).

III. Rubrics of the desired collaborative behaviour. The authors prepared the rubric on the desired collaborative behaviour based on Hesse et al.'s (2015) operationalization of collaborative aspects.

\subsection{Context and participants}

The study was conducted at two technical universities in ESP classes for computer science students. First and second year students were selected for this study. The sample for observation included 56 students from Kaunas University of Technology and 54 from Vilnius Gediminas Technical University. All students were observed while working collaboratively on the described tasks and field notes were taken. After the completion of the intended tasks, researchers conducted semi-structured interviews. Fifteen respondents ( 8 from one university and 7 from another) were interviewed. The interviewing was ceased after data saturation was achieved.

\subsection{Data collection and analysis}

The qualitative language-based data from both interview transcripts and participant observation field notes (from both universities) was collated since the researchers had no intention to compare findings from the students of two institutions. The researchers aimed to find out what challenges and opportunities were experienced by students while engaged in the activities developing collaboration in ESP courses. Inductive data analysis strategy was applied, and categories emerged from the data, which were answers to the research question. The qualitative data analysis procedure followed the guidelines suggested by Merriam and Tisdell (2016). Data analysis started during the process of data collection. After the researchers had first observational data of the first collaborative task, they gathered for collective coding. Data was read several times and notes next to bits of data that seemed relevant and answering the research question were made. It was the process of open coding that resulted in a set of codes that were initial responses. The same open coding procedure was applied to the observational data of the rest collaborative tasks and data from semi-structured interviews. Later, the researchers applied analytical coding during which they tried to group codes into fewer and more general categories. They had regular meetings via Skype to code the data collectively.

To ensure internal validity and credibility, the researchers used triangulation - the bestknown strategy for qualitative research (Merriam \& Tisdell, 2016). It included the use of multiple methods for data collection (observations and semi-structured interviews), multiple sources of data (data collected through observations at different times and classes) and multiple investigators (more than one researcher was collecting and analyzing data). In addition, the researchers took the stance of practitioner researchers. Practitioner research or the notion of 'inquiry as a stance' involves the idea that knowledge on how to enhance students' learning and develop proper learning environments can be better achieved not by researchers working outside the classroom but by the ones that are practitioners who are 
engaged in inquiry at the same time (Cochran-Smith \& Lytle, 2009). Such roles facilitate the practitioners' decisions on what and how something should be done in real classrooms.

\section{RESULTS}

The analysis of qualitative data revealed five categories and subsequent subcategories. The first three categories revolved around positive aspects: improved $21^{\text {st }}$ century skills, enhanced collaboration quality, and improved ESP learning. The other two were negative: insufficient collaboration and prevailing traditional perception of ESP learning. The following positive aspects of collaborative activities were observed by teachers and perceived by students:

\section{Improved $21^{\text {st }}$ century skills}

Improved problem solving and critical thinking. Teachers' observations revealed that engagement into various collaborative tasks which included activities aimed at improving collaboration skills resulted in the development of diverse 21 st century skills in students. Due to the provided tools (online collaborative problem-solving environment), students approached the problem-solving task in a more structured manner and displayed a deeper understanding of problem-solving as well as spent more time on representing the problem.

During the semi-structured interviews students commented: "I realised that when we combine our opinions, we can arrive at better solutions"; "We do not need to rush when trying to understand the problem, we rather have to consider all the possible aspects"; "I understood that it is necessary to spend additional time for reading on the issue because only in this case you are able to provide arguments for and against."; "I felt that I would feel uncomfortable when not knowing how to explain my choice."; "Whenever you are asked to think about all possible supporting statements, you are implicitly made to spend more time on reading about the issue".

Improved ICT skills. Findings from observations revealed that students discovered previously unfamiliar online tools. Most students did not know any mind mapping and crowdsourcing tools. Some students were also unaware of the collaborative presentation creation possibilities offered by Google Slides and Prezi.

During the semi-structured interviews, students expressed positive attitudes towards exploring these tools: "I was happy to learn about new features of Prezi since then you can make presentations quicker and better." or "I liked learning about the tool of mind mapping which I am going to use in my studies". One individual comment highlighted the importance of this skill: "We usually spend too much time on Facebook and do not know how to use more diverse tools for our studies and collaborative work...we should keep up with the latest advances in the field of technology".

Enhanced creativity. The researchers observed that the outcomes of the tasks were of higher quality in comparison to what students usually accomplish individually. Students produced more creative results of the collaborative problem-solving tasks, as they were expected to generate ideas to solve the problem by applying divergent thinking, i.e., explore as many different solutions as possible.

The quotes from the semi-structured interviews were: "I really liked the way my groupmate applied the magazine template for our presentation, I thought it was really 
creative and I learned from him"; "We approached the problem from a different point of view"; "I think that the feature of Google slides that allows slides to rotate like a cube is very attractive. I would definitely use it in the future"; "No doubt, our presentations were more interesting in comparison to the ones we could prepare individually".

\section{Enhanced collaboration quality}

Improved attendance. Students, who were informed that assessment covered their collaborative efforts, showed improved attendance in classes where they had to perform collaborative assignments. Such a shift in student attendance demonstrates their awareness that the tasks in question could not be postponed. The researchers observed that some students who usually skip a large number of classes would turn up for collaborative activities. The semi-structured interviews revealed that better attendance was achieved due to the sense of shared responsibility: "...we attended better because it was our common project..."; "...there is no way to escape from collaborative tasks".

Changed quality of talk. Both lecturers observed that students often reminded each other the ground rules that encouraged everyone to share their ideas and criticize by providing arguments only, and to maintain a friendly atmosphere. Students answers included: "I liked the idea of ground rules and their short ideas"; "...we kept them on our table...when he missed the class we joked that he broke these rules"; "I was reminded constantly to provide arguments for my suggestions"; "He kept engaging into arguing too often but the rules before his eyes kept telling him to stay friendly and I think it worked".

Improved task-regulation. The researchers observed that the number of distractions declined since students monitored each other and were informed about this aspect of assessment in advance. If earlier some students were frequently checking their smartphones' screens, now they commented: "I had to participate equally and show efforts since I knew that my friend will be assessing my performance”. Generally, the field notes also indicated that students were rather focused on the task and spent less time multitasking. Students were active while discussing the ways tasks could be completed and the progress each group made.

\section{Improved ESP learning}

More speaking time. The researchers observed that the mode of learning where student groups work simultaneously gives students much more time to practice language use. Notably, researchers observed a significant increase in speaking time. The student comments in the semi-structured interviews confirmed these observations: "...and it is a very good idea to speak in groups, it helped a lot with English, you have to speak English whether you want it or not, and it is like this for an hour and a half' and 'if we had the possibility to speak for at least a few likes this, for an hour and a half...", "It really changed and the more you spoke the easier it was to express yourself in English, we generally tried to speak English all the time, there were no times when we did not, although there were some people who had difficulties, I had them too, I will not lie".

Less communication reticence. The researchers observed that students experienced less communication anxiety. Those who did, experienced it only temporarily, usually during the first minutes of group discussions. Later, students encouraged each other and managed to overcome this obstacle. Their comments were: "For the very beginning, I felt that my poor English prevents me from expressing ideas but later I somehow started 
talking and forgot my fear"; "...seeing others not caring about the mistakes they make I felt less stressful about it too"; "...without all class and a teacher listening to my talk, it was much easier to communicate just in group"; "...I thought I would not speak, because I cannot really speak English. But I did, I spoke a lot". 'What we improved? Vocabulary, or perhaps simply the courage to speak".

Improved engagement and attitude towards ESP. The researchers observed more active participation on students' behalf. From researchers' field notes: "I have never seen them work so actively, gave a lot of pluses for active participation". Students commented on their engagement in the interviews: "...it is really nice to share your ideas with someone else, because these ideas are also nice and help the group, ... friendship was on a higher level, as such is the manner of collective work that you have to make concessions and arrive at common decisions"; "I prefer the kind of tasks when you are not alone and get help from the rest. I liked such the tasks during our classes".

Students perceived the following drawbacks/challenges experienced while performing collaborative activities.

\section{Insufficient collaboration}

Prevailing cooperation. Analysis of the data revealed that students did not always collaborate as expected. Researchers noticed that: "after classes students discussed how to divide labour and work individually" and "... said he would take care of the first part of the presentation, focus on the other parts". In semi-structured interviews students also commented on certain instances of failure to collaborate: "I am usually the kind of person who does everything alone, I really like working individually, I do everything by myself and I care about others..."; "All the activities in the classroom were conducted together, we worked jointly during classes, did everything together, but when we had to meet outside classes or work together from home, only me and one other student worked, we did not collaborate the way we were supposed to".

Lack of collective responsibility. Yet another problem observed by the researchers was that not all students assumed equal amount of responsibility for completion of their tasks: "some students only arrived for presentation of the results". Students also seemed to have been concerned by the attitude of some of their colleagues: "My colleague was in a different group and she also mentioned that three people or so in her group would come only for the final presentations, you know, when everything is finished. They would stand beside their group mates and then leave. They have not contributed in anyway whatsoever..."; "In our group some people displayed passiveness towards work generally. Some people simply cared about completing the task, not the quality of work. It really depends on a person .... I have always tried to carry out tasks in such a way that would bring satisfaction for me".

Lack of experience and understanding of collaboration. Another issue pointed out by the students was that they had little or no prior collaboration experience, thus it was difficult for them to grasp the idea of collaboration in the beginning. As noticed by one student: "I do not know really, maybe it is because it was this new experience for us, the real team work, I do not even have what to compare it with, to say that something was wrong. Because usually, it is as you say, we do something separately, we divide work, bring it all together and deliver. But here, everything was different, I do not even know what the shortcomings are" or "...it was to me, because at school and even now at the university, we divide tasks before classes, you know, I do this you do that, you speak about this, I will speak about that. That is all the teamwork...". 


\section{Traditional perception of ESP learning}

Individual outcomes prevail over collective outcomes. The researchers noted that in some cases students' individual outcomes prevailed over collective outcomes: "there was a number of questions related to the possibility of getting a better mark rather than improving shared result". Although the findings from observations revealed that the majority of the students have found these kind of activities acceptable, there were those who were not satisfied with such approach to learning, mostly due to the assessment of collective outcomes. The semi-structured interviews have also revealed that students had varied attitudes towards collaborative activities: "the kind of 'we will not need this in the future" attitude, I do not know, maybe we will not need it in life. It is like when you study maths and people keep telling you that you will not need it in life. Perhaps it's the same, people think they will not need it in the future"; "It was unexpected to have so many collaborative tasks"; "...it is easier when you have a coursebook and do traditional tasks".

\section{DISCUSSION}

The provided collaborative tasks and additional measures to enhance collaboration yielded several beneficial results. Completion of the tasks has led to the development of collaboration skills, as well as some other most important $21^{\text {st }}$ century skills, such as problem-solving, critical thinking, creativity, and ICT skills. The importance of these skills is recognized by policymakers, who included them into various frameworks that describe skills required for success in the $21^{\text {st }}$ century (Hakkinen et al., 2017). The fact that the significance of these skills is widely recognized points to the fact that the tasks suggested by the authors of the paper are the right choices for educational designers of modern ESP classes. Such tasks meet the requirements for the action-oriented approach by allowing students to achieve not only linguistic goals (Piccardo \& North, 2019). The provided tasks enabled the holistic development of students' skills. For example, they were beneficial for the development of problem-solving skills, which also implies the development of creative thinking. Given the increasing popularity of learning in the context of problem solving, they were most useful for the stage of representation or conceptualization of ill-structured problem-solving process. Although it is considered as the most important stage when solving ill-structured problems, usually problem solvers do not devote enough time and effort for it (Hung, 2013). Also, the majority of students are proficient in using technology for social media; however, when it comes to the use of digital tools in education, they usually struggle to understand their potential value. With the current massive increase in the use of visuals to communicate information and knowledge in more accessible ways and a shorter time, the use of digital tools for this purpose becomes of paramount importance. The provided tasks allowed practicing the mind mapping techniques and tools for the creation of mind maps. Therefore, such tasks might help students to learn new ways of utilizing ever-advancing technological tools and aim at the enhancement of digital visual literacy, among other skills.

Most importantly, such collaborative learning scenarios improved the quality of collaboration among students. The improved attendance of those classes where learners worked on the collaborative tasks shows both increased motivation and responsibility towards the completion of the task. The created ground rules reminded students about the necessity of equal participation, shared understanding, consensus seeking, presence of 
constructive criticism, shared collaborative responsibility, proper argumentation, and conflict avoidance. Although students commented that they had enhanced their collaboration and had improved the quality of speaking, it is clear that additional supporting evidence is necessary to confirm this finding. For example, students could be asked to record their collaborative discourse, which might also serve as a measure to prevent them from switching to a native language or as a proof for each member's active contribution to the task. Moreover, students may need a more frequent practice of creating and exercising ground rules. The very process of formulating such rules may increase their awareness of the right type of collaboration. The observed increased participation in the task-regulation processes proves the fact that the given collaborative tasks improved learners' engagement. The learners felt the need to attend classes and perform tasks better because of being evaluated by other group members and, probably, because they were aware that the assessment included the evaluation of the collaborative aspects of the task. Besides, it might have reduced process losses, which is considered as a common barrier in collaboration (Steiner, as cited in Hesse et al., 2015). The study results are consistent with the conclusions of researchers (e.g., Jucevičienė \& Vizgirdaitè, 2012; Lai et al., 2017), who observed that additional measures to address collaborative skills through the application of purposefully designed tasks improves not only collaborative learning as a process but also the collaboration skills of the students.

A very promising finding is that such types of activities also contribute to various aspects of language learning, such as the increased speaking time in comparison to traditional classes, reduced communication reticence and increased overall engagement in learning ESP. Although not expressed by learners explicitly, it might be that such diverse collaborative tasks resulted in more meaningful communication among them, which in turn enhanced their engagement. Namely, the necessity of more meaningful communication in comparison to earlier approaches is highlighted by the action-oriented approach. Such findings confirm that such collaborative tasks are in line with the ones that stresses the importance of collective group work and collective problem solving (Piccardo \& North, 2019).

Despite the fact the students were provided with additional explicit measures that facilitate the development of collaboration (construction of ground rules, instruction on the differences between collaboration and cooperation as well as a rubric explaining the desired collaborative performance), these measures may have been insufficient as students experienced challenges while collaborating. They could have included intermediate and constant feedback on collaboration in different forms of assessment (teacher assessment, peer assessment and self-assessment). These results are consistent with the findings of researchers who claimed that students lacked collaboration experience and tended to cooperate during collaborative tasks (Ge \& Land, 2003; Vizgirdaite \& Jucevičienè, 2012). Such results are somewhat disappointing and confirming that it is not an easy task to develop students' collaboration skills.

Also, students' previous learning experience might have directly influenced cases when the collaboration was insufficient. The fact remains that some of them may have been unfamiliar with collaborative learning culture or assessment systems where their collaborative efforts are considered. Students are not used to being assessed for collaborative efforts in a language course, because the dominant practice is still the assessment of individual efforts. It is also likely that they were unwilling to change the practice they were familiar with for a long time. In such cases, educators should include detailed explanations of the benefits of collaboration. 
Although the action-oriented approach is indicated as the most desirable approach to modern language education (Council of Europe, 2018; Piccardo \& North, 2019), some students may prefer a traditional approach to language learning. ESP educators may influence the attitudes of students through a clear explanation of the benefits the modern approach provides.

\section{CONCLUSION}

Discussion of the results allows drawing the following conclusions:

1. ESP educators should involve language learners in collaborative learning environments more frequently because students lack collaboration skills. In addition, such learning scenarios serve many other beneficial purposes. Students can additionally develop a number of the essential $21^{\text {st }}$ century skills, such as problemsolving, critical thinking, ICT skills, and creativity, which are all critical for student success in the future.

2. As additional measures aimed at facilitating collaboration process can result in increased quality of student collaboration, ESP educators need to continue attending professional development courses on the social aspects of collaborative tasks (e.g., analysis of best collaboration practices, inclusion of students in self-assessment, application of Likert-type scales to assess various aspects of collaboration and other).

3. As the designed collaborative tasks had positive impact on ESP learning, language educators should seek to design or employ already designed similar collaborative tasks that do not limit them in linguistic goals and evoke meaningful collaborative discourse among the learners.

4. Since part of students' learning is still determined by their previous learning experience and attitude towards learning foreign languages, educators should be careful in finding the correct blend of previous learning with the new trends, which puts forward additional demands for both learners and educators.

\section{REFERENCES}

Autor, D. H., Levy, F., \& Murnane, R. J. (2003). The skill content of recent technological change: An empirical exploration. The Quarterly Journal of Economics, 118(4), 12791333.

Buzan, T., \& Buzan, B. (2006). The mind map book. Pearson Education.

Cammarata, L., Tedick, D. J. \& Osborn, T. A. (2016). Content-Based Instruction and Curricular Reforms: Issues and Goals. In L. Cammarata (Ed.), Content-based foreign language teaching: Curriculum and pedagogy for developing advanced thinking and literacy skills (pp. 1-22). NY and London: Routledge.

Chen, R. \& Hird, B. (2006). How do Chinese students collaborate in EFL group work? Prospect, 21(2), 70-81.

Cochran-Smith, M., \& Lytle, S. L. (2009). Inquiry as stance: Practitioner research for the next generation. Teachers College Press.

Council of Europe (2001). Common European Framework of Reference for Languages: Learning, Teaching, Assessment. Cambridge: Cambridge University Press. 
Council of Europe. (2018). Common European Framework of Reference for Languages: Learning, Teaching, Assessment. Companion Volume with New Descriptors. Strasbourg: Council of Europe. Retrieved from https://rm.coe.int/cefr-companionvolume-with-new-descriptors-2018/1680787989

Csapó, B., \& Funke, J. (2017). The nature of problem solving. OECD.

Fernández, M., Wegerif, R., Mercer, N., \& Rojas-Drummond, S. (2001). Re-conceptualizing "scaffolding" and the Zone of Proximal Development in the context of symmetrical collaborative learning. The Journal of Classroom Interaction, 50(1), 40-54.

Ge, X., \& Land, S. M. (2003). Scaffolding students' problem-solving processes in an illstructured task using question prompts and peer interactions. Educational Technology Research and Development, 51(1), 21-38.

Häkkinen, P., Arvaja, M., \& Mäkitalo, K. (2004). Prerequisites for CSCL: Research approaches, methodological challenges and pedagogical development. In K. Littleton, D. Faulkner \& D. Miell (Eds.), Learning to collaborate and collaborating to learn (pp. 161-175). New York: Nova Science Publishers, Inc.

Häkkinen, P., Järvelä, S., Mäkitalo-Siegl, K., Ahonen, A., Näykki, P., \& Valtonen, T. (2017). Preparing teacher-students for twenty-first-century learning practices (PREP 21): a framework for enhancing collaborative problem-solving and strategic learning skills. Teachers and Teaching, 23(1), 25-41.

Hesse, F., Care, E., Buder, J., Sassenberg, K., \& Griffin, P. (2015). A framework for teachable collaborative problem solving skills. In P. Griffin, \& E. Care (Eds.), Assessment and teaching of 21st century skills: Methods and approach (pp. 37-56). New York: Springer.

Hung, W. (2013). Conceptualizing problems in problem-based learning. In J.M. Spector, B. B. Lockee, S. Smaldino, \& M. Herring (Eds.), Learning, problem solving, and mindtools: Essays in honor of David H. Jonassen (pp. 174-194). Upper Saddle River, NJ: Routledge.

Jonassen, D. H. (2011). Learning to solve problems: A handbook for designing problemsolving learning environments. NY and London: Routledge.

Jonassen, D. \& Land, S. (Eds.). (2012). Theoretical foundations of learning environments. $\mathrm{NY}$ and London: Routledge.

Jucevičienè, P., \& Vizgirdaitè, J. (2012). Educational empowerment of collaborative learning at the University. Social Sciences, 75(1), 41-51.

Lai, E., DiCerbo, K., \& Foltz, P. (20 17). Skills for today: What we know about teaching and assessing collaboration [White paper]. London: Pearson. Retrieved from http://www.p21.org/storage/documents/Skills_For_Today_SeriesPearson/Collaboration_White_Paper_FINAL.pdf

Li, H., \& Liu, Y. (2011). A brief study of reticence in ESL class. Theory and Practice in Language Studies, 1(8), 961-965.

Mercer, N. (2002). Developing dialogues. In Wells, G., \& Claxton, G. (Eds) Sociocultural perspectives on the future of education. Learning for Life in the 21st Century (pp. 141154). Blackwell, Oxford.

Mercer, N. (2009). Developing argumentation: Lessons learned in the primary school. In Muller Mirza and A.-N. Perret-Clermont (Eds.), Argumentation and Education: Theoretical Foundations and Practices (pp. 177-194). Springer International Publishing.

Merriam, S. B., \& Tisdell, E. J. (2016). Qualitative research: A guide to design and implementation. San Francisco, CA: Jossey-Bass. 
Miyazoe, T., \& Anderson, T. (2012). Discuss, reflect, and collaborate: A qualitative analysis of forum, blog, and wiki use in an EFL blended learning course. ProcediaSocial and Behavioral Sciences, 34, 146-152.

Newman, J. H. (1889). The Idea of a University. London: Longmans, Green and Co.

Piccardo, E. (2014). From communicative to action-oriented: A research pathway. Curriculum Services, Canada. Retrieved from https://transformingfsl.ca/wpcontent/uploads/2015/12/TAGGED_DOCUMENT_CSC605_Research_Guide_English -01.pdf

Piccardo, E., \& North, B. (2019). The action-oriented approach: a dynamic vision of language education. Multilingual Matters Limited.

Prichard, J. S., Stratford, R. J., \& Bizo, L. A. (2006). Team-skills training enhances collaborative learning. Learning and Instruction, 16(3), 256-265.

Rollinson, P. (2005). Using peer feedback in the ESL writing class. ELT Journal, 59(1), 23-30.

Roschelle, J., \& Teasley, S. D. (1995). The construction of shared knowledge in collaborative problem solving. In C. O’Malley (Ed.), Computer supported collaborative learning (pp. 69-97). Berlin, Heidelberg: Springer-Verlag.

Saavedra, A. R., \& Opfer, V. D. (2012). Learning 21st-Century Skills Requires 21stCentury Teaching. Phi Delta Kappan, 94(2), 8-13.

Schwab, K. (2017). The fourth industrial revolution. Crown Business.

Shehadeh, A. (2011). Effects and student perceptions of collaborative writing in L2. Journal of Second Language Writing, 20(4), 286-305.

Strijbos, J. W., Martens, R. L., Jochems, W. M., \& Broers, N. J. (2004). The effect of functional roles on group efficiency using multilevel modeling and content analysis to investigate computer-supported collaboration in small groups. Small Group Research, $35(2), 195-229$.

Turuk, M. C. (2008). The relevance and implications of Vygotsky's sociocultural theory in the second language classroom. Arecls, 5, 244-262.

Vizgirdaite, J. (2013). Educational empowerment of student collaborative learning in the university studies. (Doctoral dissertation, Kaunas University of Technology, Lithuania).

Vygotsky, L. (1986). Thought and language. Cambridge: MA.

Wang, Y. C. (2015). Promoting collaborative writing through wikis: a new approach for advancing innovative and active learning in an ESP context. Computer Assisted Language Learning, 28(6), 499-512.

Warwick, P., \& Mercer, N. (2011). Using the interactive whiteboard to scaffold pupils' learning of science in collaborative group activity, presented at 14th Biennial EARLI Conference for Research on Learning and Instruction, Exeter, United Kingdom. Retrieved from https://www.semanticscholar.org/paper/Using-the-interactive-whiteboardto-scaffold-pupils-Warwick-Mercer/76ebad39cc295fecf62292e2ce9c81c52702646

World Economic Forum. (2016). The future of jobs. Employment, skills and workforce strategy for the fourth revolution (Global Challenge Insight Report). Retrieved from http://www3.weforum.org/docs/WEF_Future_of_Jobs.pdf 